\title{
Positive psychology as a counterweight to youth economic deprivation
}

\author{
Tamara Hovorun ${ }^{1}$, Kulpreet Kaur $^{1}$, Hanna Ryk $^{2}$, Olha Lomak $^{2}$, and Oksana Kikinezhdi ${ }^{3, *}$ \\ ${ }^{1}$ Jindal Institute of Behavioural Sciences of O.P. Jindal Global University, Sopinat, Haryana, India \\ ${ }^{2}$ Hryhorii Skovoroda University in Pereiaslav, Department of Psychology, 30 Sukhomlynsky Str., Pereiaslav, 08401, Ukraine \\ ${ }^{3}$ Ternopil Volodymyr Hnatiuk National Pedagogical University, 2 Maksyma Kryvonosa Str., Ternopil, 46000, Ukraine
}

\begin{abstract}
The article deals with the topical problem of economic deprivation of young women and men and alternatives for overcoming it through the introduction of the psycho-correctional practices of positive psychology. The subject of the study is to find out the gender symmetry or its violation in the position of the subjectivity of genders in the choice of life activity strategy. The conceptual model of positive psychology and its components as the indicators of the psychological state of young women and men in personal and professional self-determination are presented. The social and psychological factors that determine the satisfaction of the youth with the choice of a job and its content, the ability to direct and adjust the requests and motivations of young women and men in searching for a more successful professional and social status have been substantiated. It has been found out that overcoming gender inequality in social and economic gender expectations, and a sense of economic deprivation of the youth is possible by internalizing the basic principles of personality self-determination through learning, and involvement in positive psychology. Egalitarian orientations concerning the importance of receiving professional education and developing adequate personality qualities are important for youth but especially for young women's internal subjective well-being experience. Satisfaction with social environment and confidence in the coming day the most common international concepts of economic happiness for group youth psychology.
\end{abstract}

\section{Introduction}

COVID-19 affected all layers of the population economically and deepened the level of youth "relative deprivation" as the perception of oneself (family or one's own reference group) as less economically prosperous. Self-esteem, being an indicator of a socially less successful economic personal or group compared to others, has always been much higher for the students and working youth. It is young people entering adulthood who have to face such socio-economic challenges as the need to find the desired professional activity and opportunities to achieve it, pay for vocational education or living separate from the family, look for a job without the necessary level of professional qualifications and work experience, support their own financial needs related to the age interests of the youth and more. Eric Erickson by no coincidence found an all-embracing psychological definition of this age stage in the periodization of personality development: identification versus isolation. The process of creating identity occurs during adolescence, but primarily takes place in early adulthood,in soudens years. Reaching adulthood in modern society is not always a linear or clean transition. As generations continue to adapt new adult markers are created that add different social expectations to what it means to be an adult.

\section{Problem statement}

Experiencing relative economic deprivation as a psychological source of personal unhappiness due to the un fulfillment of many social and basic needs, ways to correct toxic thoughts and find positive meanings in overcoming internal conflicts is one of the areas of positive psychology, which explores the factors of personal subjective well-being (SWB) [1].

Positive psychology explains why the level of youth aggression (various types of crime), when many young people with their inability to accept socio-economic challenges and implement ways of overcoming them, is higher in authoritarian countries, where the share of the middle economic class is low and there is a significant economic difference in the incomes of the upper, middle and lower classes.

Why do the very youth need special psychological support? Because the youth without a proper professional and educational level create a vicious circle of poverty reflection when young people start families that, due to low economic levels, do not have a sufficient level to meet the material and spiritual needs of their own children who, like their parents, are not able to achieve a sufficient level of education, as well as professional in the near future, which poverty again reproduces a new circle of poverty,

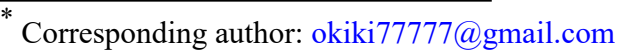


so called vicious circle $[2,3,4,5]$. The results of the researches testify the difference of value attitudes towards material enrichment of the student youth, which underwent socialization within the framework of market and planned socialist economy $[6,7,8]$.

Gender-specific problems in young adulthood are observed in double employment of women, their lower economic status, the level of payment. Even in democratic egalitarian societies dominate the ideas of exploiting onesex responsibility (man is the main breadwinner and the dominative social and personality expectations from women-to stay at the role of mother, children and caregiver for elderly members of the family) $[9,10,11$, $12,13]$. So the main spheres of her subjective well-being in self-realization, working activity and developing personality habits, skills and knowledge is in family settings. Every new generation continues to adapt new adult markers and create that add different social gender expectations to what it means to be a professional and economically sufficient adult.

The experience of European countries is considered to be the most effective regarding implementation of the positive actions on achieving gender equality. Council of Europe Gender Equality Strategy (2018-2023) focus on six strategic areas: 1) to prevent and combat gender stereotypes and sexism; 2) to prevent and combat violence against women and domestic violence; 3) to ensure the equal access of women to justice; 4) to achieve a balanced participation of women and men in political and public decision-making; 5) to protect the rights of migrant, refugee, and asylum-seeking women and girls; 6) to achieve gender mainstreaming in all policies and measures [14].

If the concept of economic culture in the past was mainly characterized in the financial categories such as expenditures, profits, income, etc., today the economic categories are inseparable from the civilizational principles of providing them with certain legal and moral principles. That is why a set of internal and external factors that have caused the frustration of certain social needs is always considered in the process of analyzing the various causes of protest youth economic movements.

Among them, the degree of satisfaction or dissatisfaction with their social and economic status due to the frustration of a ging demands in the psychological theory of economic deprivation [15]. The relative economic deprivation as a source of the frustration occurs in comparison with others, such as the average income of women with average income of men. At the same time, the greater the level of "relative deprivation" is the greater the mass of protest, often aggressive, angry behavior.

Without stopping on the consequences of gender economic deprivation, which are widely presented in the scientific literature $[16,17,18]$, we want to draw attention to the ways of overcoming it through the application of the principles of positive psychology, which is capable of activating personal potential of an individual in overcoming traditional gender stereotypes $[12,13,19,20$, $21,22]$. After all, if the position of women is assessed according to their economic status, both in relatively economically prosperous societies and in those that are just getting on the rails of a market economy, it will occupy the lowest level.

Since the subjective sense of well-being mediates any sphere of human activity, a lot of research in positive psychology is devoted to the problem of the relationship between professional work and a sense of satisfaction with it, including the research of the factors for happiness. Although mindfulness is integrated in many positive psychology manuals as a "positive" technique, they have hardly developed the implications of their use or have investigated the relationship between mindfulness and human well-being [23, 24, 25, 26, 27, 28].

The opinion of the co-founder of the principles of positive psychology M. Seligman referring to the understanding of the significance of the doctrine of roles in young adulthood states that "The positive emotions of confidence hope and trust, for example, serve us best not when life is easy, but when life is difficult. In times of trouble, understanding and building the strengths and virtues like valor, perspective, integrity, equality, loyalty - may become more urgent than in good times" [1, p. 322].

The study aims is to find out the gender symmetry or its violation in the psychological background personality position of the genders SWB in the choice of professional, working life activity strategies.

\section{Conceptual models}

Progress in psychological measuring of happiness has been made in understanding the components of SWB: there is no gender correlation between estimation material prosperity and possibility to get perfect professional education and happiness of youth the adaptation, goals and meanings, the cultural influences national indicators of happiness [29].

The favor to the gender division of personal selfrealization spheres into male (subject-instrumental) and female (guardian-expressive), is inherent in young men and women with traditional orientations, often as an example of parental imitation. The adherents of egalitarian equality have constructed an androgynous, multidimensional concept of building not only a professional career but also a family one on the basis of the interchangeability of family roles and ignoring the role in their construction of gender. Such universalization of family and professional roles of the genders was motivated, among other things, by the factor of the possibility of achieving the fullness of happiness and life satisfaction in equal partnership.

It is important to note that a happy partnership and personal self-realization at work, as an indicator of internal satisfaction of the position of positive psychology, as indicators of a happy life, is the openness to the new experiences and at the same time self-reliance, actualization of self-aspirations, self-sufficiency, selfperception without protective mechanisms, stereotyped expectations, the position of subjectivity in life. 


\section{Goals and objectives of the research}

The object of the study was-socio-psychological factors that determine the SWB of the university students as the strivings for the necessity of developing basic professional skills and opportunities future job activities and accepting its demands and personality expectations. The discovering subjective gender differences in meanings, strivings and abilities concerning the requests and motivations for future economic status.

The subject of the study was to find out the gender symmetry or its violation in the position of the students subjectivity in the choice of life activity strategy.

The main hypothesis at the initial stage of the study was the assumption that young people's individual acceptance of patriarchal gender culture which may be observed difference in personality internalized descriptive, indicative or directive-prohibitive sex stereotypes may reduce and limit the level of desirable work positions in developing subjectivity as reflection of professional abilities, career aspirations, demonstration of individual self-presentation. Traditional gender orientations motivate manifestations of polarization of life spheres and self-realization as among female as well as among male students.

The methods of the research included a complex of complementary techniques (theoretical analysis of the achievements of positive psychology; conducting genderhomogeneous, gender-mixed focus groups, content analysis of finishing sentences as short students answers to opened questions connected with the topic: "It's me in 10-15 years" standardized A. Matchak psycho diagnostic test [30].

Gender differences have been noted and compared in the construction of individual scenarios of future socioeconomic life in the time perspective in 10-15 years with the dominative content of individual oral narratives fixed in focus groups discussions. The standardized individual interviews have been conducted was with those young women striving for success in professional non-traditional careers, such as police, military, or IT spheres as well for women and males with strict traditional gender orientations. Egalitarian orientations concerning the importance of receiving professional education and developing adequate personality qualities are important for all young people, but especially for young women's internal subjective-being experience. Different kinds of external or internal factors of students function can determine their subjective well-being in chosen professional education or in starting point of practice searching for the desirable economic status. But the quest for youth meaning is a key part of what makes males and females self-assertive in everyday activities coming toward the desirable financially sufficient constant not temporary status.

Satisfaction with social environment and confidence in the coming day are the most common international concepts of happiness on the individual and group youth psychology including gender.

In total, 298 students (180 female students and 118 male students) participated in the research.

\section{The results of research}

The data obtained in the research study confirm the results of our previous studies, namely the fact of more purposeful development of the image of economic "I" in male students due to higher coherence of affective, cognitive and behavioral components with internalized traditional gender stereotypes concerning the importance for male persons SWB reaching material and financial status and for the women's SBW to have such husband $[21,22,31,32]$. Female youth more accept emotions connected with subjective working experience with such emotions as fear, sadness, or anxiety as indicators of unhappiness. Male youth are more likely to overcome them.

Female students show a higher level of intimate competence as an important component of social competence (the method "Questionnaire of three types of competence”, A. Matchak [30]) (Fig. 1).

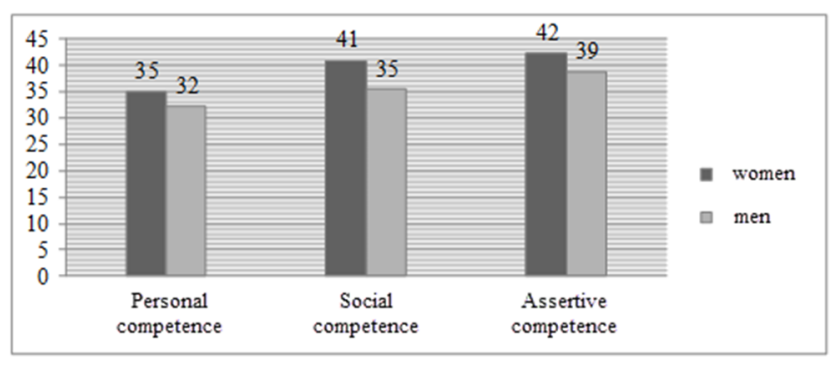

Fig. 1. An average values by "Three types of competence questionnaire" methodology.

Annex to figure1- steins raw results to women and men in: personal competence: females $35-37=3$, males $29-33=2$; social competence: females $39-41=5$, males $33-35=3$; assertive competence: females $42-45=5$, males, $39-41=4,5$.

They are also able to successful presentation their skills and qualities in the social exposition situation compared with the lower men's indicators, which reflecting the ability to be guided by certain standards of presentation of their own professional ability in situations where the person is at the center of attention. Young women are more focused on social interaction than young men; they are characterized through more communicative persistence in the process of doing professional duties. Comparison of the self-determination scale indicators in values of life demonstrates higher results of male selection, reflects their unconditional acceptance of their own life activities, higher self-confidence in successful professional self-actualization.

According to the assessment economic position and "happy human being" turned out to be a significant factor determinates gender difference in economic strivings and professional expectations (Table 1).

The content analysis of the student's narratives as well as discourses of focus groups discussions (Questions for discussion like "What social environment influence make you more happy?", "What kind of your educational activity make you happier?" etc.) demonstrated the manifestation of gender stereotypes in economic and financial spheres (in youth the design of the concepts of femininity as economic objectivity; masculinity as 
economic subjectivity and androgynous as gender neutral).

Table 1. The degree of assimilated traditional stereotypes by students (in \%).

\begin{tabular}{|l|c|c|l|}
\hline $\begin{array}{c}\text { Varieties } \\
\text { (character) of } \\
\text { gender } \\
\text { prescriptive } \\
\text { stereotypes }\end{array}$ & $\begin{array}{c}\text { Percentage of } \\
\text { egalitarian } \\
\text { stereotypes in } \\
\text { the form of } \\
\text { women and } \\
\text { men Self }\end{array}$ & $\begin{array}{c}\text { Percentage of } \\
\text { patriarchal } \\
\text { stereotypes in } \\
\text { the form of } \\
\text { women and } \\
\text { men Self }\end{array}$ & $\begin{array}{c}\text { Varieties } \\
\text { (character) of } \\
\text { gender } \\
\text { prescriptive } \\
\text { stereotypes }\end{array}$ \\
\hline $\begin{array}{l}\text { Descriptive } \\
\text { (orienting) }\end{array}$ & $25 \%$ & $75 \%$ & $\begin{array}{l}\text { Descriptive } \\
\text { (orienting) }\end{array}$ \\
\hline $\begin{array}{l}\text { Prescriptive } \\
\text { (evaluating) }\end{array}$ & $10 \%$ & $90 \%$ & $\begin{array}{l}\text { Prescriptive } \\
\text { (evaluating) }\end{array}$ \\
\hline Proscriptive & $2 \%$ & $98 \%$ & Proscriptive \\
\hline
\end{tabular}

Young women in evaluating SWB in themselves demonstrated a higher level of self-satisfaction in such aspect of it as moral acceptance, coherence of moral views with real behavior, their own ability to manage people than their male counterparts. At the same time, women show a much higher level on the scale of "protective strengthening of self-esteem", which indicates, on the one hand, a certain degree of acceptance of one's Self and, on the other, a fear of possible rejection of oneself, rejection of significant others, desire to show oneself in a better way.

In our view, such a gender disparity of results testifies to the greater subordination of a woman's life scenarios, her goal setting and self-realization to the effects of traditional gender stereotypes, which increase a woman's anxiety before expecting to have children, motherhood, a combination of professional and home responsibilities, which affects the corresponding anxious reflection of woman's own meanings of being.

Thus, the dilemma of self-determination in the choice of professional and family roles in the young adulthood demonstrates the negative power of the psychological impact of stereotypes, compliance with which does not allow young people to meet the need for individual choice. On the contrary, the adoption of egalitarian culture, which gives them a feeling of happiness through the strengthening of self-confidence, performs an energysaving function in building family relationships, educational, professional and career growth. It should be noted that the modern female students are more psychologically adapted to functioning in the future "male world", more successful in mastering political, managerial roles, unusual professions than males, who find it difficult to be involved in the household guardianship and parental roles, teaching professions, family circle; etc. However, those women, who are ready to play on the "male field", still taste androcentric behavior: in the role of leaders they are going to adapt men's management styles, evaluate economy and career aspirations through the prism of "male" needs and demands, ready take on additional household responsibilities, exacerbating, exasperate the phenomenon of double employment. Nevertheless male financial happiness was related more to being a taker rather than a giver, whereas meaning of women's economic aspirations were related more to being a giver than a taker.

One of the objectives of the study was to identify alternatives to economic deprivation, including its gender aspect, by applying the psycho correctional personality (individual) approaches.

Positive psychology considers the personality achievement in any kind of self-realization through the prism of adherence to happiness as the intersection between pleasure and meaning. Among set of meanings are the principles of rationality as consciousness and using in practice thought full ways to achieve prosperity, understanding the necessary educational and professional means to achieve it, the consistency of different kinds of economic activity on the legal principles adopted in the nearest social environment. This refers not only to the standards that correspond to the release of some educational product, but also the development of personality features of economic behavior (e.g., frugality, self-assertiveness).

The prestige is the principle of economic activity, which deals not only with the place of work, shopping, but also, above all, with the self: the social status of the profession, working skills and abilities, career economic opportunities, holding a position and career perspectives, the uniqueness of possibility to realize the main meanings of the own Self. The prestige forecast of the chosen profession is an important indicator of the students economic culture, which sometimes have been motivated by "fashionable" professions, such as law or IT, and does not take into account their connection with personality inclinations- However, many young people started to notice, that the profession should be in need in far future on the contrary to choosing in soviet times a foreign language translator, which lost its prestige in terms of globalization and open borders.

Altruism is a positive psychology principle that testifies to the extent of the sacrifice for the material support of others: families, elderly parents, orphans, people with special needs. It is not only about charitable activities for the benefit of those who need help, but also about conscious self-sacrifice, self-denial for the economic benefit of others, which brings satisfaction, raises self-esteem. Thus, the key principles of positive psychology of getting satisfaction from economic activity, its pleasure allows not only to be financially supported, but also to have positive emotions to work. Their implementation requires proper psychological counseling of the youth, professional diagnostics and professional selection, which predicts the possibility of satisfaction with the chosen activity as a basic motive for its economic success.

Disclosure of the psychology of gender differences in the economic behavior of the student youth, the ability to be guided by economic principles at different levels of material functioning has a hidden psychological basis such as a positive objective attitude to their personal economic potential and prospects for its application (selfreflection). It is this basis that dictates the different economic behavior of men and women in terms of limited material resources and expanding the range of personal needs. Thus, in addition to the internality of the locus- 
control, the principles that ensure positive thinking play an important role in achieving the desired status of economic well-being and overcoming the psychological pressure of gender stereotypes.

It is known that in positive psychology the feeling of satisfaction, happiness, well-being is divided into two types: hedonistic as situational pleasure, which is usually short-term, sensory according to the external source of pleasure and value, intra-personal. The latter is achieved when a person manages to achieve meaningful goals, objectives, sense of life. That is why this kind of positive experiences is called the result of value-semantic wellbeing, realization of personal potential.

Discussions about which satisfaction brings more comfort and pleasure hedonistic, situational or valuesemantic, show that the latter is the most preferable, because it is able to shift deep emotions, raise self-esteem, prolong the feeling of happiness. The example of one of the student groups, which instead of celebrating the prom, decided to donate the saved money to the orphanage for the needs of local children deprived of parental attention, can be illustrative in this respect. At the same time, proms were quickly erased from the memory of other student groups, but those who organized a holiday for children remembered this for many years and celebrated the memorable event.

Although positive psychology considers both sources of satisfaction equally important and denies personal selfrealization as a higher level of satisfaction, its basic postulates are based on the importance of experiencing a state of passion for activity, absorption by its essence, fascination with their achievements. The culture of human economic existence is precisely to maximize the longterm achievements of material support for the realization of vital goals and to minimize situations of the lack of funds. It is no coincidence that poverty is considered the greatest human defect, and material prosperity is a necessary condition for the personal freedom.

If we apply the model of the founder of positive psychology M. Seligman [1, 29] to the economic wellbeing of a person, then personal achievements according to his theory of well-being depend on the implementation of basic conditions, such as: inclusion in the activity, passion for it, satisfaction with interpersonal relations with people, realization of the sense of their activity and its achievements. Such conditions of the personalized activity can be realized both at the level of microeconomics (household, smallholding, etc.) and at the macro level.

If the proposed conceptual model of life satisfaction of positive psychology is compared with the social situation of student youth development, then its structural components can act as a prognosis and at the same time a diagnosis of psychological states of a young person (wellbeing or dissatisfaction with life), who masters the basics of their profession, determine their future material status. Indicators of their present and most importantly future psychological well-being can be indicators of the wheel of fortune by M. Seligman, namely confidence in the right choice of professional self-determination and its personal significance, consistency of the chosen path with their own life values, belief in their own ability to fully realize their potential with maximum dedication and in harmonious relationships with others.

The results of research of emotions nature, their impact on a person suggests that the strength of positive and negative emotions are different, that is the well-being of the individual depends on their proportion, the share of both, their ratio in life. According to the research done by representatives of positive psychology, the negative emotions reduce the life satisfaction much more than the same amount of positive ones. The ratio of negative to positive is $3: 1$, that is bad is much stronger in terms of influence than good.

Theoretical principles of positive psychology prompted us to find the adequate to its conceptual provisions focus groups and training programs with emphasis on the development of the youth ability, regardless of gender, to establish social relations with other people, involve in professional activities in the present and in the future, to realize their views on life, meaningful life orientations, to achieve success.

\section{Discussion}

According to positive psychology the more people felt their activities were consistent with the core of themselves, the desirable values of their self, the greater meaning they report in their dream about and real professional choice.

According to some male opinion (youth with egalitarian gender orientations in focus-group discussions) scarcity of money in performing some desirable for them "female" professions (teacher, medical nurses, preschool educator, library worker etc.) reduced possibility for self-realization, when possibility for happiness less possible in comparison to meaning. Desirable for youth social-economic status, professional male's and female's self-image is formed depending on gender orientations.

Students with egalitarian gender attitudes of both sexes perceive satisfaction with the chosen educational profession as a source of economic activity, which is connected with internal work satisfaction-positive personality traits: the capacity to love chosen vocation, feelings to be proud of it ("we are future teachers", "psychologists", “journalists"), independence and creativity in individual performance of working duties, effective interpersonal skills, talent of personality growth in everyday practice and experience.

Prioritize in economic well-being of students with traditional gender orientations are connected mostly with external work satisfaction factors: less strongly with subjective activity, personality determination, mostly with objective circumstances of working duties, the salary level, relations with the colleagues.

The collected empirical data suggest that the social roles of men and women are still largely mediated by gender stereotypes, which serve as a guide in differentiating the areas of their economic selfexpression, determining the life scenarios declared by students and views on material obligations. However, the 
realities of the economic functioning of genders have formed a greater personal potential of women in the development of traditionally male economic space, the trigger for which will be the dominant over patriarchal egalitarian ideas of personal professional selfpresentation.

\section{Conclusions}

Overcoming gender inequality in social and economic status, in particular a sense of economic deprivation is possible by internalizing the basic principles of economic culture through learning, development, involvement in positive psychology.

Pilot testing of a number of questionnaires allowed us to identify the most adequate structural research methods for the identifying feeling of economic youth economic well-being and economic self-deprivation such as the degree of self-reflection and satisfaction by chosen kind of the professional education, as well in the self-analyzing the obtained working experience as skills, abilities and habits which will are in needs for the future professional activities.

Gender difference in the level of self-reflective estimation by students the necessary social and professional abilities have been investigated by the complex methods including A. Matchak psychological test for study the social competences as abilities to perform and be successful in close interpersonal contacts, in actualizing the self in wide social communication and exposition and in social environment demanding assertive behavior. The measurement of such working abilities and skills considered the psychological background of SWB in successful performance any professional job activities and usually considered more often by male population.

The study results exposed higher development of social competences in female students especially among those who are adhered to egalitarian gender culture. Female and male students with traditional attitudes to profession division and household duties, social activities for men's and women's are less optimistic in the individual subjective wellness in reaching the desirable economic status relationships with others, absorption, realization of the Self in a personally significant social activity, its conformity to own system of views, life values.

The realities of gender economic functioning especially among young women oriented on egalitarian sex relationships have shaped their greater personal professional potential and readiness of in intromission to the traditionally masculine economic professions-spheres. The trigger mechanism in striving SWB in economic status is in overcoming patriarchal ideas of bipolar personal professional self-presentation among youth.

Egalitarian attitudes and behavior are more likely help youth to open ourselves up to positive psychology in financial success on the way of their professional education. Gender differences in expected economic wellbeing and real strivings are best predicted by difference in gender orientations, personal vision on goal attainment and high self-esteem or self-efficacy, but not sex belonging. It is important for youth to feel belongingness in a society and it social care and psychological guardian ship, so they can develop their full working potential and achieve self actualization.

Internalizing egalitarian gender culture can enhance the individual economic activity, increase the motivation for self-development in professional education.

\section{References}

1. M. E. P. Seligman, Authentic happiness: using the new positive psychology to realize your potential for lasting fulfillment (New York, 2002)

2. G. Hofstede, Masculinity and Femininity: The Taboo Dimension of National Cultures (Thousand Oaks, SAGE Publications, 1998)

3. J.-S. Hyde, Half the Human Experience: The Psychology of Women (Heath and Company, Lexington-Massachusetts-Toronto, 1991)

4. M. Kimmel, The Gendered Society (Oxford University Press, New York, 2000)

5. C. P. Chen, Career self-determination theory. Psychology of Career Adaptability, in Employability and Resilience (2017), p. 329-347, https://cutt.ly/QzW8aoF. Accessed 21 Mar 2021

6. N. Garg, S. Singh, Financial Literacy among the Youth. International Journal of Social Economics 45(1), 173-186 (2018)

7. R. Berger, Why Financial Literacy in Higher Education is a Top Future-Ready Skill. https://www.forbes.com/sites/rodberger/2019/07/24/ why-financial-literacy-in-higher-education-is-a-topfuture-ready-skill/\#7adbba761767 (2019). Accessed 12 Mar 2021

8. A. Pandey, R. Gupta, Entrepreneur's Performance and Financial Literacy - A Critical Review. International Journal of Management Studies 5(3) (2018). doi:10.18843/ijms/v5iS3/01

9. O. Hankivsky, A. Salnykova, (eds.) Gender, politics, and society in Ukraine (University of Toronto Press, Toronto, 2012)

10. Women and Men in Leadership Positions in Ukraine. A Statistical Analysis of Business Registration Open Data. https://cutt.ly/S7Dpe (2017). Accessed 12 March 2021

11. I. Faljosa, L. Vodjanka, Ghenderna nerivnistj na rynku praci Ukrajiny (Gender Inequality in the Ukrainian Labor Market). Modern problems and ways of their solution in science, transport, production and education 26(2), 45-47 (2014)

12. M. M. Skoryk, Gender Discrimination in Access to Labor and Services: Estimate of the State of Implementation. Anti-Discrimination Directives of Council of EU by Ukraine: analytical study (Biuro sotsialnykh ta politychnykh rozrobok, Kyiv, 2017)

13. T. Marcenjuk, Krashhi praktyky zabezpechennja ghendernoji rivnosti na roboti: mizhnarodnyj dosvid i Ukrajina (The Best Practices for Implementing 
Gender Equality at Work: International Experience and Ukraine). Ja 36, 16-21 (2014)

14. Council of Europe Gender Equality Strategy 20182023 (Council of Europe, Strasbourg, 2018), https://rm.coe.int/strategy-en-20182023/16807b58eb. Accessed 12 Mar 2021

15. Susan T. Fiske, Social Beings - a core motives approach to Social Psychology (John Wiley and Sons, Danvers, 2004)

16. J. Bosak, S. Sczesny, A. H. Eagly, Communion and agency judgments of women and men as a function of role information and response format. European Journal of Social Psychology 38, 1148-1155 (2008)

17. D. Burgess, E. Borgida, Who women are, who women should be: Descriptive and prescriptive gender stereotyping in sex discrimination. Psychology, Public Policy, and Law 5, 665-692 (1999)

18. A. H. Eagly, Sex difference in social behavior a social role interpretation (Erlbaum, Hillsdale, NJ, 1987)

19. U. Jakubowska, Wokol pojęcia „kompetencja społeczna" ujęcie komunikacijne. Przegląd Psychologiczny 39, 29-40 (1996)

20. Positive Psychology. A practical guide (Icon Books Ltd, London, 2012), p. 216

21. T. V. Hovorun, Why female's and male's student's self-fulfilling presentations are different? European vector of contemporary psychology, pedagogy and social sciences: the experience of Ukraine and the Republic of Poland, vol. 2 (Baltija Publishing, Sandomierz, 2018), pp. 85-103

22. T. Hovorun, V. Kravets, S. Kravets, O. Kikinezhdi, Gender Aspects of Economic Self-Presentation of Ukrainian Student. Eastern European Conference of Management and Economics, in Environmental Management and Sustainable Economic Development: Proceedings of the 2nd International Scientific Conference, ed. by L. Weis, V. Koval, K. Aškerc, Ljubljana, Slovenia, May 29, 2020 (Ljubljana School of Business, Ljubljana, 2020), pp. 355-362

23. C. P. Nichols, L. Molix, Positive psychology as social change. The Journal of Positive Psychology 8 (2), 165-167 (2013)

24. J. E. Maddux, Subjective well-being and life satisfaction. https://cutt.ly/pzW3msp (2017), Accessed 12 Mar 2021

25. A. Cebolla, A. Enrique, D. Alvear, J. Soler, J. Garcia-Campayo, Contemplative positive psychology: introducing mindfulness into positive psychology. Papeles del psicologo 38 (1), 12-18 (2017). doi:10.23923/pap.psicol2017.2816

26. J. M. Froiland, Promoting Gratitude and Positive Feelings About Learning Among Young Adults. Journal of Adult Development 25 (4), 251-258 (2018). https://cutt.ly/ozRIC6R. Accessed 12 Mar 2021
27. A. Mira, J. Bretón-López, Á. Enrique, D. Castilla, A. García-Palacios, R. Baños and C. Botella, Exploring the incorporation of a positive psychology component in a cognitive behavioral internet-based program for depressive symptoms. Results throughout the intervention process. Frontiers in Psychology 9, 2360 (2018)

28. P. L. Hill, M. Allemand, A. L. Burrow, Considering multiple methods for differentiating conceptually close constructs: Examples from the field of positive psychology. Social and Personality Psychology Compass 12 (11), e12417 (2018)

29. M. E. P. Seligman, Learned optimism: How to change your mind and your life (Vintage Books, division of Random House, Inc., New York, 2006)

30. A. Matczak, A. Jaworowska, D. Fecenec, J. Stańczak and J. Bitner, Człowiek w Pracy. CWP-podręcznik (Pracownia Testów Psychologicznych, Warszawa, 2009)

31. Y. Z. Vasylkevych, O. M. Lomak, I. M. Zozulia, D. V. Kochereva and O. M. Kikinezhdi, Creativity as a Resource of Adaptation in a Politically and Economically Unstable Environment. Journal of Intellectual Disability - Diagnosis and Treatment 8(4), 710-718 (2020). doi:10.6000/22922598.2020.08.04.14

32. O. M. Kikinezhdi, H. Ya. Zhyrska, R. S. Chip, Y. Z. Vasylkevych, T. V. Hovorun, Psychology of the Gender-Equitable Environment: Research of Problems. Journal of Intellectual Disability Diagnosis and Treatment 8(3), 538-547 (2020). doi:10.6000/2292-2598.2020.08.03.31 